\title{
Radiation Awareness amongst Junior Doctors
}

\section{Selmi $\mathrm{M}^{*}$ and Natarajan MD}

Department of Radiology, The Royal Oldham Hospital, The Pennine Acute NHS Hospital Trust, UK

${ }^{*}$ Corresponding author: Selmi M, Department of Radiology, The Royal Oldham Hospital, The Pennine Acute NHS Hospital Trust, UK, E-mail: mariyah.selmi@doctors.org.uk

Citation: Selmi M, Natarajan MD (2016) Radiation Awareness amongst Junior Doctors. J Adv Radiol Med Image 1(2): 205. doi: 10.15744/2456-5504.1.205

Received Date: September 08, 2016 Accepted Date: October 25, 2016 Published Date: October 27, 2016

\begin{abstract}
Learning objectives: To evaluate junior doctors knowledge of ionising radiation exposure to patients in routinely requested investigations.

Background: Recent literature has suggested that junior doctors' knowledge of ionising radiation is inadequate. Advances in technology and availability have led to of these investigations being readily requested. Exposure is associated with adverse risks especially malignancy; therefore in accordance with the Ionising Radiation (Medical Exposures) Regulation (IR(ME)R), clinicians should be aware of radiation doses and their legal responsibility as referrers.

Findings and procedure details: A questionnaire was circulated to all junior doctors in the hospital, referrers were asked about radiation dosing, estimation of cancer risk and knowledge of referral systems and legislation.

Overall, our results showed that knowledge on this topic was poor. Of the 49 responses received $0 \%$ correctly estimated the dose of abdominal x-rays, CT head or CT thorax, abdomen and pelvis (CT TAP) scans. $43 \%$ underestimated the radiation dose of CT TAPs despite $89 \%$ of responders routinely requesting this investigation. $27 \%$ of responders thought that MRI and Ultrasound used ionising radiation. A total of $49 \%$ and $43 \%$ correctly estimated the risk of inducing malignancy in CT TAP and Chest X-ray respectively. 1/49 doctors knew of any legislation and could name IR(ME)R, 0/49 knew the Royal College of Radiologists i-Refer guidelines.
\end{abstract}

Conclusion: Knowledge of radiation doses, responsibility of referrers, and risk to patient safety was extremely limited. Education of junior doctors needs to be expanded to impress the importance and serious implications of these aspects. Possible solutions to implement this have been discussed.

Keywords: Radiation Awareness; Patient Safety; Education; Dosimetry

List of Abbreviations: CT: Computed Tomography; CXR: Chest X-Ray; CT TAP: Computed Tomography of Thorax Abdomen and Pelvis; NICE: National Institute of Health and Care Excellence; F1: Foundation Year 1 Trainees; F2: Foundation Year 2 Trainees

\section{Introduction}

Radiation awareness is a topic sparsely covered in both undergraduate and postgraduate curriculum in the United Kingdom [1]. Limited knowledge particularly amongst junior doctors is well documented [2-7]. At the forefront of patient care, junior trainees generally have less understanding of the basic sciences of imaging techniques, often opting for more generalised studies rather than tailored investigations which answer the specific clinical question $[5,8]$.

Almost every speciality requires the input of a radiological investigation to diagnose and determine management plans for patients. Ranging from a staging CT in oncology, to interventional endovascular treatments; radiology continues to play a key role [9,10].

Although radiation-associated risks are well documented [11-14], the relative amount of teaching on this topic is minimal, with image interpretation being the primary focus. In the United Kingdom, studies have shown that radiation from diagnostic imaging leads to between 100-150 deaths annually [15]. With continuing advances in technology, imaging techniques such as CT are readily available; therefore every effort has to be made to reduce radiation doses to patients [16].

Every imaging department works towards the principle of achieving the best quality images with the lowest reasonably achievable dose of radiation (ALARA) [17,18]. Optimisation techniques during image acquisition such a beam collimation, $\mathrm{x}$-ray filtration and tube current modulation, as well as setting CT parameters in accordance with patient weight, are well documented techniques used by scanner manufacturers and practitioners to protect patients from unnecessarily high doses of radiation [19-22]. However, in order to reduce cumulative lifetime doses, which may ultimately lead to detrimental effects, referrer's need to request every investigation appropriately and justify that the clinical benefit gained from the study will outweigh the potential harm from ionising radiation. 
The updated British Safety Standards Regulation and the Ionising Radiation (Medical Exposures) Regulation 2000, both detail the safety measures required to insure there are no unnecessary radiation exposures, and that each member of the team is aware of their legal responsibility. There is now a greater onus on the referrer to be involved in the justification process and communicating potential risk to patients and carers [23,24].

The Health Protection Agency UK estimates the risk of radiation based on effective dose (E) [25]. The absorbed dose is the mean energy transferred to mass by ionising radiation. Once corrected for the type of radiation, it represents the equivalent dose. The equivalent dose is further weighted for specific tissues and organs, which are summated to produce the whole body dose in a specific examination $[22,26,27]$.

These values are used as reference ranges to provide thresholds of safe levels of exposure in diagnostic imaging and to estimate the probability of risk of inducing fatal malignancy, as well as genetic detriment from irradiation during imaging25. The risk model set out in the International Commission on Radiation Protection (ICRP) publications is based on a 'reference person' of average age, gender, nationality and sex, derived from data of 7 populations (Shanghai, Osaka, Nagasaki, Hiroshima, Sweden, UK and USA), and hence can only provide a probability of risk [28-31]. An American study showed only 7\% of patients were counselled regarding risks prior to their CT scan and only $9 \%$ of doctors routinely discussed radiation doses, suggesting that an understanding of these key concepts is vital to gain informed consent for imaging investigations [32].

A study by Puri et al., demonstrated that on retrospective reflection, 78\% of emergency doctors in their study group felt between $25-50 \%$ of CT studies conducted were probably unnecessary; suggesting that proper evaluation and justification of risk/benefit for every investigation needs to be common practice to reduce unnecessary radiation doses to patients and wastage of resources $[33,34]$.

The study also showed that clinicians with more clinical experience were more likely to explain the risks of radiation as well as look at previous exposures before requesting [33]. This suggests, in conjunction with gaining clinical experience, if junior doctors receive adequate radiation awareness training in the early formative stages of career development; this may lead to responsible requesting of investigations and regular communication of risks with patients as standard in their future career [1,6].

We aimed to evaluate junior doctors' knowledge of ionising radiation exposure to patients in routinely requested investigations and whether current teaching is adequate to arm doctors with the knowledge to request appropriate investigations in accordance with guidelines.

\section{Materials and Methods}

We conducted a prospective observational study, where a 9 point questionnaire (Figure 1) was circulated to all foundation year 1 and 2 trainees attending mandatory weekly teaching at the Royal Oldham Hospital Manchester UK (part of the Pennine Acute Hospital Trust). Foundation 1 and 2 years are the 2 years of mandatory training following a minimum of 5 years undergraduate training at medical school, where basic minimum competencies of clinical care are met.

Trainees were not informed of the study prior to being given the questionnaire and the completed surveys were collected at the end of the unrelated teaching session. The survey focussed on three themes. Firstly, teaching experience and investigations used in clinical practice. Secondly, understanding of radiation doses and associated risks; and finally, knowledge of legislation and guidelines. The data was then collated using Microsoft Excel and statistical analysis of question 5 data was performed using an independent t-test.

\section{Results}

A total of 70 questionnaires were distributed to the junior trainees, forty-nine fully completed questionnaires returned (response rate $70 \%)$. Results are described in relation to the theme.

\section{Theme 1: Teaching and current practice}

Questions 1 and 2 showed that only 24\% of foundation doctors had had previous radiology teaching on dosimetry in diagnostic imaging either since starting training or at medical school. In practice, the most commonly requested imaging investigations were chest x-rays (98\%), abdominal x-rays (96\%), ultrasound studies (90\%) and CT thorax-abdomen-pelvis (CT TAP- 82\%).

\section{Theme 2: Radiation exposure and associated risk}

Questions 3-6 of the questionnaire explored participants knowledge of radiation doses. 18\% of trainees correctly identified a chest $\mathrm{x}$-ray having the equivalent radiation dose of 3 days annual background radiation. Table 1 outlines the equivalent of doses of radiation associated with different radiological imaging studies compared to the radiation exposure from one single chest $\mathrm{x}$-ray. Despite $90 \%$ of trainees identifying a CT TAP as having the highest dose of radiation out of the options, $56 \%$ and $59 \%$ of foundation 1 and 2 doctors respectively underestimated the radiation dose of a single study and 51\% overall underestimated the lifetime risk of inducing a fatal malignancy (1:2000). There was no statistical significance between the correct responses of 
foundation 1 and 2 trainees ( $\mathrm{p}=0.5995$ ). Interestingly $20 \%$ of trainees believed MRI studies to be associated with radiation doses and $5 \%$ of foundation 2 trainees associated ultrasound with radiation.

1) Have you had any formal teaching on radiation doses in diagnostic imaging? Yes No

2) Which investigations do you routinely order as a foundation doctor? (Please circle all that may apply)

\begin{tabular}{|c|c|c|c|c|c|c|}
\hline $\begin{array}{l}\text { Chest } \\
\text { X-ray }\end{array}$ & Ultrasound & & CT Head & CT Thorax & MR & Abdominal \\
\hline
\end{tabular}

3) Which one of the following has the highest radiation exposure?

\begin{tabular}{|c|c|c|c|c|c|}
\hline $\begin{array}{l}\text { Chest } \\
\text { X-ray }\end{array}$ & Ultrasound & $\begin{array}{l}\text { Barium } \\
\text { studies }\end{array}$ & CT Head & $\begin{array}{l}\text { СT Thorax } \\
\text { Abdomen Pelvis }\end{array}$ & MRI \\
\hline
\end{tabular}

4) How does the radiation dose from a chest $x$-ray compare to the annual dose of background radiation?
0 days
3 days
1 week
1 month 1 year
10 years

5) What is the relative equivalent radiation dose in 'Chest $\mathbf{x}$-rays' for the following investigations? (e.g. equivalent dose of a skull $x$-ray $=50$ chest $x$-rays)

Chest $\mathrm{X}$-ray $=$

Abdominal $X$-ray $=$

Barium swallow =

CT Head $=$

СT Thorax Abdomen and Pelvis =

$M R I=$

UItrasound $=$

6) What is the lifetime risk of inducing a fatal cancer by performing the following tests? (please circle one of the following)

\begin{tabular}{|c|c|c|c|c|c|}
\hline CT TAP & $1 / 100$ & $1 / 2000$ & $1 / 25000$ & $1 / 1000000$ & $1 / 10000000$ \\
\hline CXR & $1 / 100$ & $1 / 2000$ & $1 / 25000$ & $1 / 1000000$ & $1 / 10000000$ \\
\hline
\end{tabular}

7) Are you aware of the formal legislation regarding radiation doses for diagnostic imaging? Yes No (If yes please specify which legislation you have come across)

8) Are you aware of the national referral guidelines for requesting investigations? Yes No (If yes please specify which guidelines you have come across)

9) What does the acronym "ALARA" represent? 


\section{Theme 3: Knowledge of guidelines and legislation}

Questions 7-9 showed 94\% of trainees were unaware of any legislation relating to radiation awareness or dosing and only 12\% knew of any referral guidelines to aid in choosing the correct imaging investigation. None of these trainees were able to name i-Refer as a source, but had used the National Institute of Health and Care Excellence (NICE) CT head guidelines [35]. 10\% could correctly describe the acronym ALARA to mean 'as low as reasonably achievable'.

\begin{tabular}{|c|c|c|c|c|}
\hline Investigations & \multicolumn{2}{|c|}{ Correct Responses (\%) } & \multicolumn{2}{c|}{ Underestimates (\%) } \\
\hline CXR & F1 & F2 & F1 & F2 \\
\hline Abdominal x-ray & 0 & 96 & 0 & 0 \\
\hline Barium Swallow & 0 & 0 & 94 & 84 \\
\hline CT Head & 0 & 0 & 94 & 80 \\
\hline CT TAP & 0 & 0 & 59 & 36 \\
\hline $\begin{array}{c}\text { Magnetic } \\
\text { resonance imaging }\end{array}$ & 82 & 76 & 0 & 0 \\
\hline Ultrasound & 100 & 84 & 0 & 0 \\
\hline
\end{tabular}

CXR = Chest $\mathrm{x}$-ray; A single arbitrary unit equating to the radiation dose of a single CXR

Participants asked to estimate the radiation doses of different imaging modalities compared to the number of chest $\mathrm{x}$-rays

Table 1: Responses to the radiation exposure component of the questionnaire outlining correct responses and underestimates of radiological investigations

\section{Discussion}

Overall our results demonstrate that knowledge of radiation awareness amongst junior doctors is poor, a similar trend is seen in studies in the UK and abroad [2-4,36-40]. A limited understanding of radiation doses and associated risks may lead to unnecessary exposures, with lifetime cumulative doses potentially leading to fatal malignancies $[11,14,41]$.

Exposure is associated with adverse risks such as skin erythema, hair loss, sterility and malignancy [42-44]. Doses as low as $10 \mathrm{mSv}$ (the dose of a CT thorax abdomen and pelvis) will induce a fatal malignancy in 1 in 2000 patients [14,16]. With 51\% of our cohort underestimating this risk, it is imperative that junior doctors have up to date knowledge of radiation doses, and routinely communicate the risk and benefits of these investigations with patients to obtain informed consent $[41,45]$.

Often there may be multiple investigations, which will answer the clinical question. The Royal College of Radiologists 'i-Refer' guideline is a comprehensive online pathway which details symptoms, the most appropriate imaging investigation, and information on radiation dosing [34]. Training and access to this guideline needs to be encouraged as $88 \%$ of our cohort had no knowledge of this essential tool which could help reduce the number of unnecessary requests and potential risks to patients.

Ultimately, teaching and continued training will help to improve doctors understanding of radiology. 5\% of trainees associated ultrasound with radiation exposure despite $90 \%$ routinely requesting this modality. This has also been seen in other studies where $4-15 \%$ of doctors incorrectly considered ultrasound to use radiation $[8,37,44,46,47]$. Teaching needs to focus not only on image interpretation, but also on the fundamental science of the imaging techniques [48].

The Royal College of Radiologists has a detailed curriculum outlining teaching topics and cases [1]. These could be implemented at a postgraduate level, as $76 \%$ of trainees had had no formal teaching during their formative stages of career development. This theme is consistent with similar studies where $68 \%-70 \%$ of doctors surveyed felt they needed more radiology teaching [6,49,50]. Interestingly our study showed no statistical significance in correct responses between foundation 1 and 2 trainees. In an Australian study responses regarding radiation awareness from junior and senior emergency department doctors were similar ( $\mathrm{p}=0.75)$ [49], suggesting more clinical experience did not necessarily equate to increased knowledge in this subject and the need for continued development and training is essential.

In order to increase radiation awareness amongst junior doctors, we suggest incorporating a teaching session at induction training outlining the associated radiation risks of certain imaging investigations, how to access i-Refer guidelines, and how to effectively communicate the risks and benefits of these investigations to patients. We also suggest producing patient information leaflets for imaging involving radiation, which can be given prior to an investigation as part of gaining informed consent. We feel this would be beneficial to medical staff to insure patient safety.

\section{Conclusion}

Knowledge of radiation doses, awareness of responsibility of referrers, and risk to patients was extremely limited amongst junior doctors. Education needs to include not only image interpretation, but radiation awareness as well. Focussing on these aspects will move towards minimising wastage of resources, reducing unnecessary radiation exposures and improving patient safety. 


\section{Acknowledgement}

With thanks to the Pennine Acute NHS Hospital Trust junior doctors for their participation.

\section{References}

1. Jacob J, Paul L, Hedges W, Hutchison P, Cameron E, et al. (2016) Undergraduate radiology teaching in a UK medical school: a systematicevaluation of current practice. Clin Radiol 71: 476-83.

2. Soye JA, Paterson A (2008) A survey of awareness of radiation dose among health professionals in Northern Ireland. Br J Radiol 81: 725-9.

3. Arslanoğlu A, Bilgin S, Kubal Z, Ceyhan MN, Ilhan MN, et al. (2007) Doctors' and intern doctors' knowledge about patients' ionizing radiation exposure doses during common radiological examinations. Diagn Interv Radiol 13: 53-5.

4. McCusker MW, de Blacam C, Keogan M, McDermott R, Beddy P (2009) Survey of medical students and junior house doctors on the effects of medical radiation: is medical education deficient? Ir J Med Sci 178: 479-83.

5. Brown N, Jones L (2013) Knowledge of medical imaging radiation dose and risk among doctors. J Med Imaging Radiat Oncol 57: 8-14.

6. Nyhsen CM, Lawson C, Higginson J (2011) Radiology teaching for junior doctors: their expectations, preferences and suggestions for improvement. Insights Imaging 2: 261-6.

7. O'Sullivan J, O'Connor OJ, O’Regan K, Clarke B, Burgoyne LN, et al. (2010) 2group An assessment of medical students' awareness of radiation exposures associated with diagnostic imaging investigations. Insights Imaging 1: 86-92.

8. Zhou GZ, Wong DD, Nguyen LK, Mendelson RM (2010) Student and intern awareness of ionising radiation exposure from common diagnostic imaging procedures. J Med Imaging Radiat Oncol 54: 17-23.

9. European Society of Radiology (2010) The future role of radiology in healthcare. Insights Imaging 1: 2-11.

10. Runge VM (2010) Advances in Diagnostic Radiology. Invest Radiol 45: 823-6.

11. Linet MS, Slovis TL, Miller DL, Kleinerman R, Lee C, et al. (2012) Cancer risks associated with external radiation from diagnostic imaging procedures. CA Cancer J Clin 62: 75-100.

12. Kleinerman RA (2006) Cancer risks following diagnostic and therapeutic radiation exposure in children. Pediatr Radiol 2: 121-5.

13. Hendee WR, O’Connor MK (2012) Radiation Risks of Medical Imaging: Separating Fact from Fantasy. Radiology 264: 312-21.

14. Lin EC (2010) Radiation Risk From Medical Imaging. Mayo Clin Proc 85: 1142-6.

15. Shiralkar S, Rennie A, Snow M, Galland RB, Lewis MH, et al. (2003) Doctors' knowledge of radiation exposure: questionnaire study. BMJ 327: $371-2$.

16. Brenner DJ, Hall EJ (2007) Computed tomography--an increasing source of radiation exposure. N Engl J Med 357: 2277-84.

17. Oughton D, Hansson SO (2013) ALARA: What is Reasonably Achievable? In: Radioactivity in the Environment Vol 19, Elsevier publisher.

18. Bevelacqua JJ (2010) Practical and effective ALARA. Health Phys 2: S39-47.

19. Kalra MK, Maher MM, Toth TL, Hamberg LM, Blake MA, et al. (2004) Strategies for CT radiation dose optimization. Radiology 230: 619-28.

20. Lira D, Padole A, Kalra MK, Singh S (2015) Tube potential and CT radiation dose optimization. AJR Am J Roentgenol 204: W4-10.

21. Kalender WA, Buchenau S, Deak P, Kellermeier M, Langner O, et al. (2008) Technical approaches to the optimisation of CT. Phys Med 24: 71-9.

22. Dougeni E, Faulkner K, Panayiotakis G (2012) A review of patient dose and optimisation methods in adult and paediatric CT scanning. Eur J Radiol 81: e66583.

23. Mundig S (2011) Revision of the euratom basic safety standards directive-current status. Radiat Prot Dosimetry 144: 12-6.

24. Health and Safety (2000) The Ionising Radiation (Medical Exposure) Regulations 2000, UK.

25. Hart D, Hillier MC, Shrimpton PC (2010) Doses to Patients from Radiographic and Fluoroscopic X-Ray Imaging Procedures in the UK - 2010 Review. Health Protection Agency Centre for Radiation, Chemical and Environmental (HPACRCE034) 1-95.

26. Fowler JF (2010) 21 Years of biologically effective dose. Br J Radiol 83: 554-68.

27. Newman B, Ganguly A, Kim JE, Robinson T (2012) Comparison of different methods of calculating CT radiation effective dose in children. Am J Roentgenol 199: W232-9.

28. Eckerman K, Harrison J, Menzel H-G, Clement CH (2013) ICRP Publication 119: Compendium of Dose Coefficients based on ICRP Publication 60. Ann ICRP 42: e1-130.

29. ICRP Publication 110 (2009) Publication 110 Adult Reference Computational Phantoms ICRP. Ann ICRP. 39: 10.1016/j.icrp.2009.07.004.

30. Brenner DJ (2012) We can do better than effective dose for estimating or comparing low-dose radiation risks. Ann ICRP 41: 124-8.

31. ICRP (2007) ICRP 103: The 2007 Recommendations of the International Commission on Radiological Protection. Ann ICRP37: 10.1016/j.icrp.2007.10.001.

32. Lee CI, Haims AH, Monico EP, Brink JA, Forman HP (2004) Diagnostic CT Scans: Assessment of Patient, Physician, and Radiologist Awareness of Radiation Dose and Possible Risks. Radiology 231: 393-8.

33. Puri S, Hu R, Quazi RR, Voci S, Veazie P, et al. (2012) Physicians' and midlevel providers' awareness of lifetime radiation - Attributable cancer risk associated with commonly performed CT studies: Relationship to practice behavior. AJR Am J Roentgenol 199: 1328-36.

34. PC (2014) Imaging guidelines-the RCR experience. J Med Imaging Radiat Oncol 58: 14.

35. Centre NC, Care A (2007) Quick reference guide Head injury. Nice 56.

36. Ramanathan S, Ryan J (2015) Radiation awareness among radiology residents, technologists, fellows and staff: where do we stand? Insights Imaging 6: 133-9.

37. Luk SY, Leung JLY, Cheng CS (2010) Knowledge of radiation dose and awareness of risks: A cross-sectional survey of junior clinicians. J Hong Kong Coll Radiol 13: 189-94.

38. Sin H-K, Wong C-S, Huang B, Yiu K-L, Wong W-L, et al. (2013) Assessing local patients' knowledge and awareness of radiation dose and risks associated with medical imaging: A questionnaire study. J Med Imaging Radiat Oncol 57: 38-44.

39. Szarmach A, Piskunowicz M, Świętoń D, Muc A, Mockałło G, et al. (2015) Radiation safety awareness among medical staff. Pol J Radiol 80: 57-61. 
40. Sukumar S, Rajagopal K, Sabu K (2013) Perception of radiation awareness among medical doctors in India. Int J Pharm Biol Sci 3: 371-6.

41. Lam DL, Larson DB, Eisenberg JD, Forman HP, Lee CI (2015) Communicating potential radiation-induced cancer risks from medical imaging directly to patients. AJR Am J Roentgenol 205: 962-70.

42. Yurt A, Çavuşoğlu B, Günay T, (2013) Evaluation of Awareness on Radiation Protection and Knowledge About Radiological Examinations in Healthcare Professionals Who Use Ionized Radiation at Work. Mol Imaging Radionucl Ther 23: 48-53.

43. Cousins C, Sharp C (2004) Medical international procedures-reducing the radiation risks. Clin Radiol 59: 468-73.

44. Uri IF (2012) Lack of radiation awareness among referrers: Implications and possible solutions. Int J Clin Pract 66: $574-81$.

45. Dauer LT, Thornton RH, Hay JL, Balter R, Williamson MJ, et al. (2011) Fears, feelings, and facts: Interactively communicating benefits and risks of medical radiation with patients. AJR Am J Roentgenol 196: 756-61.

46. Paolicchi F, Miniati F, Bastiani L, Faggioni L, Ciaramella A, et al. (2016) Assessment of radiation protection awareness and knowledge about radiological examination doses among Italian radiographers. Insights Imaging 7: 233-42.

47. Famurewa OC, Obiajunwa PO, Elusiyan JB, Ibitoye BO (2014) Radiation dose and radiation protection principle awareness: a survey among Nigerian paediatricians. Niger Postgrad Med J 21: 28-33.

48. Oris E, Verstraete K, Valcke M; ESR Working Group on Undergraduate Education (2012) Results of a survey by the European society of radiology (ESR): Undergraduate radiology education in Europe-influences of a modern teaching approach. Insights Imaging 3: 121-30.

49. Keijzers GB, Britton CJ (2010) Doctors' knowledge of patient radiation exposure from diagnostic imaging requested in the emergency department. Med J Aust 193: 450-3.

50. Nyhsen CM, Steinberg LJ, O’Connell JE (2013) Undergraduate radiology teaching from the student's perspective. Insights Imaging 4: 103-9.

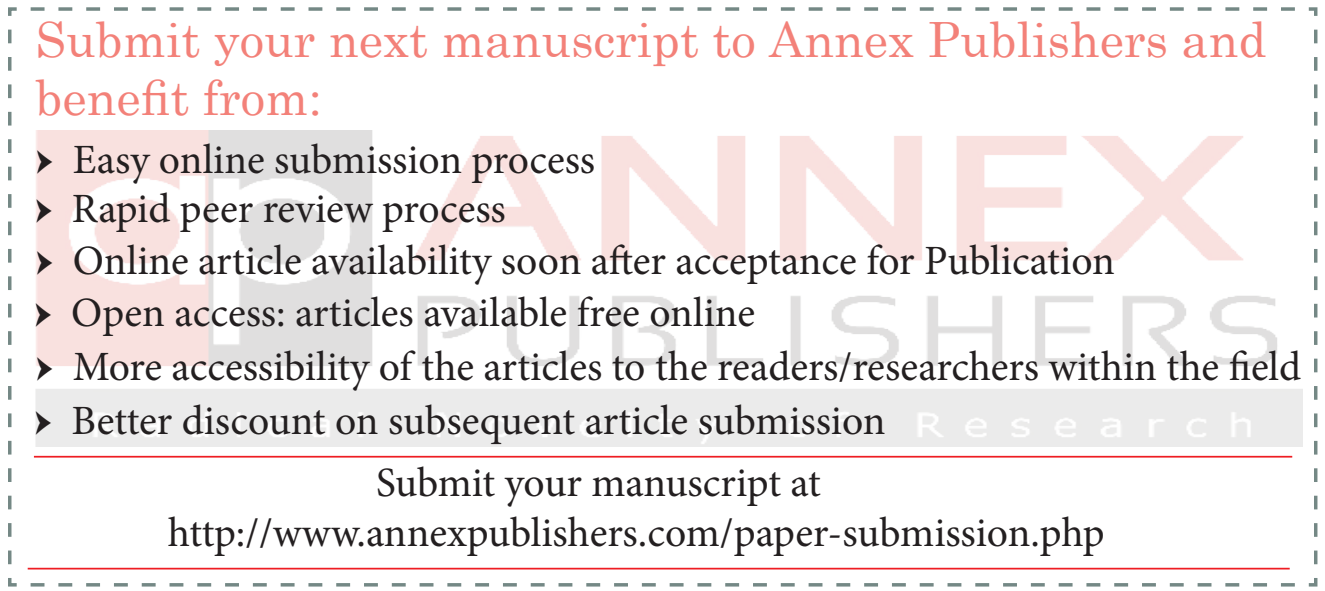

